\title{
POLÍTICA CRIMINAL DE LOS DELITOS CONTRA LA VIDA HUMANA INDEPENDIENTE EN EL PROYECTO DE CÓDIGO PENAL DE 1992 *
}

\author{
BERNARDO DEL ROSAL BLASCO \\ Catedrático de Derecho Penal \\ de la Universidad de Alicante.
}

1. No hace mucho tiempo, un significado representante de nuestra doctrina penal ${ }^{1}$ afirmaba que «los delitos contra la vida humana independiente no sólo poseen una función dogmática, sino político criminal fundamental», pues, «mediante ellos se diseñan los criterios rectores del tratamiento de los tipos integrantes de la parte especial» $\mathrm{y}$ «son también adoptadas las decisiones valorativas a que serán referidas las demás figuras de delito». De esta manera, y en nuestra opinión con sumo acierto, se estaba poniendo de manifiesto la importancia que tiene, a la hora de valorar una propuesta de nuevo texto punitivo - como la que ahora nos ofrece el Gobierno a través de su Proyecto de Código Penal de 1992 (en adelante PCP1992) —, la concreta configuración que en ella se haga de los delitos contra la vida humana humana independiente. Porque, además, en estos delitos, como en pocos, se proyecta con suma fuerza el trasfondo ideológico que subyace tras todo el Código penal, ya que si se acepta —como nosotros lo hacemos— que «una de las cuestiones en donde más aflora la ideología de un Código penal es la relativa a la eficacia del consentimiento del titular» ${ }^{2}$, en los delitos contra la vida no se puede obviar una toma de postura acerca de tan debatida cuestión. Son estas las razones que nos impulsan a analizar, con cierto detenimiento, los criterios político criminales sobre los que se estructuran, en el PCP 1992, los delitos que atentan contra el bien esencial de la vida humana independiente. No obstante, y antes de entrar en dicho análisis desearíamos hacer algunas precisiones.

Desde nuestro punto de vista, la configuración de los diferentes tipos penales en

* El presente texto es una versión ligeramente modificada y anotada de la conferencia impartida por su autor en el Ilustre Colegio de Abogados de Madrid, el día 9 d abril de 1992, dentro del curso «Política Criminal y Reforma Penal» organizado, conjuntamente, por dicho Colegio de Abogados y el Instituto Universitario de Criminología de la Universidad Complutense de Madrid.

'TORIO LOPEZ, A.: «Estudio de la reforma de los delitos contra la vida (parricidio-asesinato)», en Repercusiones de la Constitución en el Derecho Penal. Algunos problemas específicos, Bilbao, 1983, p. 79.

${ }^{2}$ LOPEZ BARJA DE QUIROGA, J.: «El consentimiento y la esterilización de los incapaces», en Cuadernos de Política Criminal, núm 44, 1991, p. 311. 
la Parte Especial de un Código ha de estar presidida por la idea de que todo el orden jurídico $-\mathrm{y}$, por lo mismo, también el orden jurídico penal- desempeña una función esencialmente protectora de bienes e intereses constituídos. Por tanto, el contenido de injusto de las diversas infracciones penales se ha de determinar, únicamente, por la medida o el grado en que dichas infracciones violan tales bienes o intereses; o lo que es lo mismo, por la medida en que violan el objeto de protección de la norma, pudiendo consistir los ilícitos penales en lesiones efectivas de los bienes jurídicos protegidos o en meras puestas en peligro de tales entidades valorativas ${ }^{3}$. Así las cosas, en los delitos que son objeto ahora de nuestra atención, el injusto específico de las diversas infracciones habrá de venir determinado por la lesión del bien jurídico en ellos protegido, que no es otro sino la vida humana del ya nacido ${ }^{4,5}$, injusto cuyo contenido no admite graduación alguna, pues la vida, o se suprime en términos absolutos, o no se suprime, pero no se puede matar más o menos, según los casos. Con ello lo que queremos expresar es que las diversas figuras de delito sobre las que se estructura, en nuestro Código penal vigente y en el PCP 1992, la protección penal de la vida de la vida humana comparten, necesariamente, un idéntico tipo de injusto, cuyo contenido se concreta en ese «matar a otro» del tipo genérico (homicidio), debiendo buscarse el fundamento de cualquier variación cuantitativa de la respuesta penal sobre presupuestos que nada tienen que ver con el núcleo esencial de tal injusto.

2. Dicho lo anterior, señalaremos que el PCP 1992 ha variado sustancialmente, respecto de lo que es la legislación vigente, la configuración esencial de los delitos contra la vida humana independiente. Las características fundamentales de tal

${ }^{3}$ Véase el planteamiento metodológico y sistemático de la teoría general del delito ofrecido en COBO DEL ROSAL, M. y VIVES ANTON, T. S.: Derecho Penal. Parte General, $3^{a}$ ed., Valencia, 1990, y la concepción del injusto que en él se preconiza.

${ }^{4} \mathrm{Se}$ ha mantenido, en nuestra doctrina, por BACIGALUPO que «aunque no sea en primera línea, ni con la misma intensidad que la vida, el delito de homicidio protege también la autodeterminación del sujeto pasivo. Tal afirmación se funda en la impunidad del suicidio establecido por el derecho vigente y presupone un objeto de protección complejo, en el que junto a la vida biológica, la autodeterminación ocupa un lugar secundario pero indudablemente relevante» (Estudios sobre la Parte Especial del Derecho penal, Madrid, 1991, p. 14). Esta tesis enlaza, directamente, con el criterio que este mismo autor - junto con otros-mantiene acerca de la naturaleza y eficacia del consentimiento como causa de atipicidad de la conducta. Para BACIGALUPO, en el caso de los bienes jurídicos de naturaleza disponible, el auténtico objeto de protección no lo constituye sólo la integridad del sustrato material en el que este objeto de protección se concreta (vida biológica, patrimonio, salud, etc.) sino que se integra, además, por la capacidad de dominio autónomo del sujeto pasivo sobre dicho objeto material, de modo que la mera lesión del sustrato material es irrelevante y «la acción sólo realiza el tipo en la medida en que importa una lesión del ámbito de dominio autónomo del sujeto pasivo: la lesión de su voluntad respecto de la conservación del bien jurídico» (Principios de Derecho Penal. Parte General, $2^{\mathrm{a}}$ ed, Madrid, 1990, p. 155. Sobre toda la problemática general de la naturaleza y eficacia del consentimiento, véase el reciente e interesante trabajo de LOPEZ-BARJA DE QUIROGA, J.: «El consentimiento...», cit., nota 2, pp. 311 ss.).

${ }^{5}$ Sobre el problema de la delimitación (límites mínimo y máximo) del objeto material en los delitos contra la vida humana independiente, véase COBO DEL ROSAL, M. y DEL ROSAL BLASCO, B.: «Artículo 407», en Alvarez García, J. y otros: Código Penal Comentado, Madrid, 1990, pp. 763-764. 
variación se concretan, en primer lugar y de forma más llamativa, en la desaparición, como tipologías delictivas con sustantividad propia respecto del homicidio, de los delitos de parricidio e infanticidio, figuras de larga tradición en nuestra legislación histórica codificada, cuyos orígenes se remontan, por lo que se refiere al parricidio, a los arts. 612, 613 y 619 del Código penal de 1882 y, por lo que se refiere al infanticidio, al art. 327 del Código penal de 1848. En segundo lugar, el texto del ahora Proyecto suprime del repertorio de las circunstancias cualificativas del delito de asesinato (art. 143) la premeditación y la inundación, el incendio, el veneno y el explosivo, en contra de lo que ha sido el criterio tradicional de nuestra legislación penal histórica, que ya las incluía como circunstancias definidoras del asesinato, cuando concurrían conjuntamente, en el art. 609 del Código penal de 1822; como circunstancias de especial agravación del homicidio, sin incluir el explosivo, en los Códigos penales de 1848 y 1850 (art. 333); o como circunstancias de cualificación del asesinato, sin incluir el explosivo, en los Códigos penales de 1870 (art. 418) y 1932 (art. 412) e, incluyendo el explosivo, en los Códigos penales de 1928 (art. 519) y 1944 (art. 406), texto, este último, que se ha mantenido vigente hasta el presente. En tercer lugar, y de conformidad con lo que ha sido durante años el criterio más extendido en las resoluciones de nuestro Tribunal Supremo, se amplía el concepto de la alevosía como circunstancia cualificativa de la figura del asesinato para dar cabida en ella, sin ningún género de duda, a lo que jurisprudencialmente se ha denominado el asesinato alevoso, ampliación que se opera por la nueva redacción que esta circunstancia tiene en el capítulo de las agravantes genéricas (art. 21, circunstancia primera) ${ }^{6}$. Además, y esto sería en cuarto lugar, el nuevo texto propuesto por el Gobierno introduce una cláusula específica de agravación cualificada de la pena para cuando en un asesinato concurrieren dos o más agravantes genéricas (art. 144). Por otra parte, en quinto lugar, el PCP 1992 viene a regular, de una forma matizadamente diferente a como se hace ahora en el texto vigente, la participación y el auxilio ejecutivo al suicidio, rebajando su penalidad relativa (es decir, por comparación a la del homicidio no consentido) y excluyendo de la punición las formas de simple complicidad (art. 147, núms 1, 2 y 3). Finalmente, y quizás dentro del capítulo de novedades más importantes, el PCP 1992 introduce, por primera vez y de forma expresa, una tipificación penal expresa para de alguna de las formas de la eutanasia consentida (art. 147, núm 4).

Aparte de ello, la nueva regulación rebaja sustancialmente las penalidades especialmente en el caso del asesinato-, tipifica expresamente la conspiración, la

${ }^{6} \mathrm{El}$ art. 10, circunstancia primera, del Código penal vigente establece que «hay alevosía cuando el culpable comete cualquiera de los delitos contra las personas empleando medios, modos o formas en la ejecución que tienden directa y especialmente a asegurarla, sin riesgo para su persona que proceda de la defensa que pudiera hacer el ofendido». Por su parte, el art. 21, circunstancia primera, del PCP 1992 establece que «hay alevosía cuando el sujeto comete cualquiera de los delitos contra las personas empleando medios, modos o formas en la ejecución que tiendan directa y especialmente a asegurarla, sin riesgo para su persona que proceda de la defensa que pudiera hacer el ofendido, o cuando el hecho se ejecutara sobre persona absolutamente indefensa». 
proposición y la provocación para cometer los delitos de homicidio o asesinato y regula, también de forma expresa, las modalidades de causación imprudente de la muerte. Estas últimas son, todas ellas, novedades impuestas por los nuevos criterios político-criminales que rigen el texto del PCP 1992 y que, entre otras cosas, diseñan un sistema punitivo en el que se rebajan, de forma general, las penalidades abstractas de las diversas figuras de delito de la Parte Especial, se suprime la punición genérica de los actos preparatorios de conspiración, proposición y provocación al delito, sustituyéndose ésta por la punición específica para algunos delitos y se deroga, igualmente, la vieja cláusula general o abierta para el castigo de la imprudencia, introduciéndose, en su lugar, una tipificación expresa de las diversas tipologías imprudentes.

3. La desaparición, como figuras delictivas con propia sustantividad, de los delitos de parricidio e infanticidio es, en cierta medida, un fenómeno legislativo esperado y ansiado por la mayoría de la doctrina penal ${ }^{7}$ que, además —en lo que al parricidio se refiere-, tendría su parangón en Códigos penales tales como el alemán, el holandés, el suizo o el austríaco. Su pervivencia en nuestra legislación penal, en cada caso por razones diferentes, ha venido siendo, de unos años a esta parte, objeto de muy severas críticas, habiéndose llegado a cuestionar su constitucionalidad, no sólo en sede doctrinal sino, incluso, desde algunas resoluciones jurisprudenciales 8 .

Y es que, efectivamente, tratar de justificar o de fundamentar convincentemente la existencia del parricidio como figura autónoma, independiente, con sustantividad y respuesta penal propia y notoriamente agravada, respecto del homicidio no es tarea en absoluto sencilla ${ }^{9}$. En alguna otra ocasión ${ }^{10}$ hemos podido poner de manifiesto que, desde una concepción predominantemente objetiva del injusto como la que preconizamos, el fundamento agravatorio del parricidio no se puede hallar sino en esa especie de doble conciencia de lo injusto, evocada por TORIO LOPEZ ${ }^{11}$, que

\footnotetext{
${ }^{7}$ En este sentido, el PCP 1992 ha ido mucho más lejos de lo que, en su momento, fueron el Proyecto de Ley Orgánica de Código penal de 1980 y la Propuesta de Anteproyecto de Nuevo Código Penal de 1983, ya que, el primero, mantuvo el parricidio en términos casi idénticos a lo que es la legislación hoy por hoy vigente (art. 157) y sustituyó la referencia al ánimo de ocultar la deshonra, en el infanticidio, por la referencia al «estado puerperal o de tensiones emocionales provocadas por las circunstancias del alumbramiento» (art. 159), mientras que, el segundo, se limitó a suprimir la consideración del conyugicidio como delito de parricidio (art. 1412), reproduciendo una fórmula muy similar a la del Proyecto del 1980 para el infanticidio (art. 143).

${ }^{8}$ Así, el Tribunal Supremo, en sentencia de 12 de mayo de 1988, no ha dudado en decir, respecto del infanticidio, que, desde un punto de vista jurídico, puede existir un choque frontal entre la figura que regula el art. 410 del Código penal y el principio de igualdad del art. 14 de la Constitución, al existir una muy llamativa desproporción entre la pena que puede ser impuesta a los «acogidos» al delito de infanticidio y la que puede recaer al resto de los ciudadanos por el mismo hecho, bien en su calidad de parricidas, bien como autores de asesinato.

${ }^{9}$ Véase, al respecto, BACIGALUPO, E.: Estudios, cit. nota 4, pp. 49ss.

${ }^{10}$ Véase, COBO DEL ROSAL, M. y DEL ROSAL BLASCO, B.: «Artículo 405», en Código Penal, cit. nota 5 , pp. 741 .

${ }^{11}$ Repercusiones, cit. nota 1, p. 88.
} 
supone desatender el mandato de respeto a la vida, desvinculándose además de las exigencias espirituales inmanentes a la relación parental. Porque, el bien jurídico que se lesiona en el delito de parricidio es la vida y el grado en el que ésta se lesiona es el absoluto. Por ello, no es posible afirmar, en sede de injusto, que matar a un pariente comporte una mayor lesión o un mayor ataque al bien jurídico que matar a un extraño ${ }^{12}$; o que comporte un más fácil acceso a la lesión del bien jurídico ${ }^{13}$; o que comporte un ataque a otros bienes jurídicos añadidos al bien jurídico de la vida. Ni siquiera por la vía de considerar que, además de un delito contra la vida, el parricidio sea un delito contra la familia ${ }^{14}$. En tal sentido, el fundamento agravatorio del parricidio frente al homicidio radicaría en una mayor culpabilidad, en el mayor reproche que se le dirige al sujeto que mata al pariente, pero siendo dicho ataque estructuralmente idéntico a éste; es decir, teniendo un idéntico tipo de injusto.

Ahora bien, si esto es así, y si, por tanto, la relación de parentesco en el parricdio se configura como una característica objetiva de la culpabilidad (o una característica de la culpabilidad formulada de modo objetivo por el legislador $)^{15}$, lo que el legislador está de esa manera estableciendo es una presunción iuris et de iure de una culpabilidad más grave; basta con comprobar la existencia del vínculo consanguíneo o conyugal, y su conocimiento por parte del sujeto activo, para que se presuma, de forma indestructible, que éste es más culpable que quien, sin más, mata a otro. El legislador se excede así, notoriamente, de sus funciones al elevar a la categoría de presunción, que no admite prueba en contrario, algo (la mayor culpabilidad) que, sin embargo, debería de acreditarse en el transcurso del proceso penal; máxime cuando tal presunción parece contradecir las conclusiones de la investigación empírica en el campo del parricidio, conclusiones que más bien apuntan a que el parricidio se presenta «como hipótesis de criminalidad atenuado, asimilable materialmente a los llamados estados pasionales por la doctrina clásica» ${ }^{16}$. En tal sentido, pues, la propuesta legislativa el PCP1992, de dejar que el parentesco juegue, en todo caso, como circunstancia de agravación general, allí donde tenga sentido que ello sea así, es un acierto que hay que aplaudir.

\footnotetext{
${ }^{12}$ Pues, obviamente, desde el punto de vista constitucional es inaceptable decir que la vida de un pariente «vale más» que la vida de un extraño.

${ }^{13}$ Porque tampoco cabe decir que, en el parricdio, se protejan «reales relaciones parentales de confianza y afecto entre las personas, y no la existencia de simples vínculos jurídicos» (BACIGALUPO, E.: Estudios, cit. nota 4, p. 51), pues la aplicación es automática, una vez se constata la relación parental y el sujeto activo conoce tal relación, al margen de cuál fuera la situación real de afecto o de convivencia entre sujetos activo y pasivo.

${ }^{14} \mathrm{Pues}$, incluso, se aplica la figura del parricidio en situaciones de separación de hecho o legal (con mantenimiento del vínculo) entre cónyuges, o en situaciones de ruptura absoluta de la idea de familia, como núcleo de relación y desarrollo personal y afectivo, como sucede en los casos de malos tratos conyugales y/o filiales, casos que, a menudo, acaban provocando una reacción parricida de los hijos o del propio cónyuge.

${ }^{15}$ Véase, al respecto, DEL ROSAL, J.: «Infanticidio (límite objetivo)», en Estudios Penales, Madrid, 1948, p. 205; TORIO LOPEZ, A.: Repercusiones, cit. nota 1, pp. 92-93.

${ }^{16}$ TORIO LOPEZ, A.: Repercusiones, cit. nota 1, p. 93.
} 
Otro tanto cabe decir de la desparición del infanticidio, aunque aquí los argumentos sean de signo un poco diferente. Su existencia como figura delictiva privilegiada respecto del homicidio resulta hoy ya, a todas luces, casi imposible de justificar. Si se pretende fundamentar en la existencia de un menor injusto, es decir, de una menor gravedad del ataque a la vida en aquellos casos en que el sujeto activo obra movido por la defensa del honor de la madre, tal fundamentación, desde la perspectiva de las valoraciones que el Derecho penal de un estado social y democrático de Derecho debe de realizar sobre lòs bienes jurídicos, no puede ser de recibo, pues la salvaguarda del honor, en un conflicto entre éste y la vida, nunca puede justificar una disminución tan notoria de las barreras defensivas del Derecho penal como la que se produce en el infanticidio. $\mathrm{Si}$, por el contrario, se pretende fundamentar, como nosotros hemos hecho en alguna ocasión ${ }^{17}$, en la general presunción que establece el legislador de que la defensa del honor represente, para determinados agentes (madre y abuelos maternos), una situación mental que les haga merecedores de un menor reproche, entonces habría, primero, que poner en cuestión el que tal suposición sea acertada, debiendo exigirse, en todo caso, la expresa prueba de ello en cada caso concreto, sin que sea posible aceptar una apreciación automática del privilegio; $y$, segundo, habría, igualmente, que objetar el hecho de que tal suposición se ciña únicamente a los supuestos de defensa del honor y no se refiera a otras situaciones anímicas por las que pueda pasar la madre en los momentos posteriores al parto.

Lo más acertado, pues, es lo que hace el texto del PCP 1992, que es suprimir la figura y dejar, en todo caso, que las reglas generales de atenuación de la pena concurran a resolver cada caso en particular.

4. El delito de asesinato, aún cuando sufre notables variaciones en su tipificación, pervive como figura autónoma, con sustantividad propia respecto del homicidio. Las dos principales modificaciones que ha introducido el legislador del PCP 1992 han sido la desaparición de la premeditación como circunstancia cualificativa del asesinato e, igualmente, la supresión como cualificadoras de tal ilícito penal de las antiguas cirunstancias de inundación, incendio, veneno y explosivo. Desde lo que han sido las exigencias doctrinales, en relación con la figura del asesinato, la desaparición de la premeditación como circunstancia cualificadora de la figura que hoy integra el contenido del art. 406 del Código penal vigente ha*de ser considerada un verdadero acierto. En primer lugar, y como ha señalado, por ejemplo, BACIGALUPO ${ }^{18}$ porque las posibilidades de encontrar un criterio de diferenciación clara entre el dolo y la premeditación, una vez se ha abandonado la vieja idea de que

${ }^{17}$ COBO DEL ROSAL, M.y DEL ROSAL BLASCO, B.: «Artículo 410», en Código Penal, cit. nota 5, p. 773; en el mismo sentido, BACIGALUPO, E.: Estudios, cit. nota 4, p. 53.

${ }^{18}$ Estudios, cit. nota 4, pp. 45ss. 
la premeditación exige una «frialdad de ánimo» ${ }^{19}$, son escasas. Por otra parte, son de sobra conocidas las críticas históricas que notables autores le dirigieron a la premeditación como circunstancia cualificativa del asesinato, bien porque se la tachó de concepto muy inseguro (von LISZT), bien porque se afirmó que es posible realizar un hecho con deliberación previa y no ser, sin embargo, objetable el motivo (HOLTZENDORFF), bien porque se dijo que una noción que, como la premedirtación, radica en hechos internos, no susceptibles de prueba objetiva o inmediata por el juez, no es adecuada para trazar la diferencia entre homicidio y asesinato (STOOSS) ${ }^{20}$. Por lo demás, y como ha señalado entre nosotros TORIO LOPEZ ${ }^{21}$, la premeditación puede ser el significante de una base psicopatológica incompatible con su estimación como culpabilidad definitivamente agravada.

Por lo que se refiere a la desaparición de la llamada circunstancia de «medios catastróficos» (la inundación, el incendio, el veneno y el explosivo), igualmente, y como en el caso de la premeditación, ésta ha de ser considerada acertada. Porque si el fundamento de su existencia, en el Código penal, como circunstancia cualificativa de dicho delito estriba en el peligro que tales medios pueden ocasionar para la generalidad de los individuos ${ }^{22}$, la desvalorización penal de este peligro puede ser ya suficientemente abarcada a través de la utilización de los mecanismos concursales, aplicando otras figuras delictivas (incendio, daños, estragos, etc.), que concurrirían en la valoración del hecho, junto con la del delito de homicidio.

El legislador del PCP 1992 ha ampliado, igualmente, el concepto de alevosía en el capítulo de las circunstancias agravantes genéricas, lo que inmediatamente repercute en la definición del asesinato cualificado por dicha circunstancia. En efecto, el nuevo concepto de alevosía que se incluye en el art. 21, circunstancia primera, del texto propuesto por el Gobierno contiene una referencia expresa a los supuestos en los que el hecho se comete sobre persona absolutamente indefensa, referencia que no se contiene, sin embargo, en la vigente definición del art. 10, circunstancia primera. Con ello, en el largo debate que desde hace tiempo se ha suscitado entre la doctrina, partidaria mayoritariamente de excluir estos supuestos de la aplicación automática del asesinato cualificado por la alevosía, y la jurisprudencia, partidaria, sin embargo, de incluirlos, el legislador de lo que pretende ser nuestro futuro Código penal ha tomado clara postura en favor de ésta última. Y es

\footnotetext{
${ }^{19}$ Idea mantenida por la jurisprudencia del Tribunal Supremo durante muchos años (véanse, por ejemplo, las sentencias citadas por ALVAREZ GARCIA, J.: «Artículo 10, núm 6», en Código Penal, cit. nota 5, p. 86), pero que ha sido rebatida por la doctrina (Ibidem) sobre la idea de que «la psicología ha puesto suficientemente de relieve que la existencia de ánimo frío entre la decisión y la ejecución, deriva del temperamento individual del sujeto, por lo que sería excesivo e injusto hacer depender la agravación de la pena de estados que son atributos de la personalidad psico-física, y no manifestaciones del proceso volitivo» (SAINZ CANTERO, J.: «Aspectos fundamentales de la circunstancia de premeditación», en Boletín de la_Universidad de Granada, 1957-1959, cit. por ALVAREZ GARCIA, J., en ibidem, p. 87).

${ }^{20}$ Véase, TORIO LOPEZ, A.: Repercusiones, cit. nota 1, pp. 109-110.

${ }^{21}$ Ibidem, p. 110.

${ }^{22}$ BACIGALUPO, E.: Estudios, cit. nota 4, p. 44.
} 
que el Tribunal Supremo, en una reiterada jurispruencia ${ }^{23}$, ha venido entendiendo tradicionalemte que dentro del delito cualificado por la alevosía es posible distinguir tres hipótesis o modalidades: el asesinato proditorio, caracterizado por el acecho, la celada, la trampa o la emboscada; el asesinato áleve, de ejecución o perpetración súbita e inesperada, desencadenándose la agresión de modo repentino e instantáneo, imprevisible e imprevisto por el ofendido; $y$, finalmente, el asesinato alevoso, en el que el agresor ejectua el hecho aprovechándose de la especial situación de desvalimiento o de indefensdión el el que se halla la víctima, situación que no ha sido provocada por el sujeto activo. Sobre tales premisas, el Tribunal Supremo no ha tenido inconveniente en considerar como alevosa la muerte de niños, ancianos y enfermos indefensos o personas desvalidas por estar privadas de razón o de sentido. Tal doctrina jurisprudencial es fruto de una consideración de la alevosía como circunstancia mixta, aunque de carácter predominantemente objetivo, consideración que parece ahora haber sido aceptada por el legislador del PCP 1992.

Sin embargo, desde nuestro punto de vista, el que el legislador haya utilizado una descripción objetiva para plasmar un determinado animus no sinifica que el sentido de la agravación sea de criterio objetivo ${ }^{24}$. La razón de ser de esta agravación radica en una actitud determinada del sujeto que trasluce un ánimo cobarde, una más firme voluntad de asegurar la lesión, a toda costa, y sin mensocabo para él, del bien jurídico $\mathrm{y}$, por lo mismo, trasluce un mayor menosprecio por el propio bien jurídico ${ }^{25}$. Así contemplada — subjetivamente-, la alevosía no concurrirá, por falta del necesario elemento anímico que exige del sujeto la inequívoca voluntad de llevar a cabo la muerte asegurándose de cualquier defensa, en aquellos casos en los que éste

\footnotetext{
${ }^{23}$ Véase una muestra de ella en la citada por COBO DEL ROSAL, M. y DEL ROSAL BLASCO, B.: «Artículo 406», en Código Penal, cit. nota 5, p. 752.

${ }^{24}$ En este sentido, COBO DEL ROSAL, M. y VIVES ANTON, T. S.: Parte General, cit. nota 3, p. 686.

${ }^{25} Y$ es que, además, desde nuestro punto de vista, no se puede decir que el fundamento de la alevosía resida en una mayor protección de la vida de los indefensos (así, GARCIA ARAN, M.: Los criterios de determinación de la_pena en el Derecho español, Barcelona, 1982, p. 150; ALVAREZ GARCIA, J.: «Artículo 10, núm 6», Código Penal, cit. nota 5, pp. 69s.), en primer lugar, porque sería tanto como decir que la vida de éstos vale tanto más que la de los no indefensos como para justificar, en cualquier situación, y sea quien sea la persona que atente contra dichas vidas, diferencias cuantitativas muy sustanciales en la pena. Por otra parte, tampoco es cierto que el Código considere más valiosas las vidas de los indefensos, y ahí está el delito de infanticidio para demostrarlo (con más detalle, COBO DEL ROSAL, M. y DEL ROSAL BLASCO, B.: «Artículo 406», Código Penal, cit. nota 5,p. 750); aparte de que ¿cómo justificar, desde el punto de vista constitucional, que «valga más» la vida de un indefenso que la vida de quien puede defenderse? Bien es cierto que esto último nos coloca frente a otro de los argumentos esgrimidos para fundamentar el mayor injusto de una muerte llevada a cabo alevosamente: la alevosía, al implicar un más fácil acceso a la lesión del bien jurídico por la utilización de medios o métodos insidiosos o clandestinos, implica un mayor contenido de injusto mayor por la debilidad a la que, en tal circunstancia, se ve sometido el bien jurídico (ALONSO ALAMO, M.: El sistema de las circunstancias del delito, Valladolid, 1982, p. 478; TORIO LOPEZ, A.: Repercusiones, cit. nota 1, p. 111). Pero lo cierto es que el Derecho penal no puede desvalorizar más unas formas de lesionar o poner en peligro el bien jurídico, que, en última instancia, no consisten sino en lesionar mejor o más certeramente el bien jurídico o en poner mejor en peligro dicho bien jurídico. Si así fuera habría que castigar más la estafa llevada a cabo con el tonto que con el listo o las coacciones llevadas a cabo con el lábil que con el que tiene una fuerte personalidad.
} 
no haya buscado expresamente tal situación, cual es la situación de la muerte de niños, ancianos o personas privadas de razón o de sentido.

Con la propuesta legal que se hace en el PCP 1992 entendemos que se desnaturaliza el verdadero sentido de la alevosía como agravante o, cuando menos, como circunstancia de cualificación del delito de asesinato - y por ello mismo entendemos que tal propuesta es rechazable--, máxime en un momento de discusión doctrinal en el que más de un autor rechaza que la alevosía, como tal, deba ser una circunstancia de cualificación del asesinato ${ }^{26}$.

5. El PCP 1992, dentro de lo que es una de sus propuestas más novedosas, por una parte, ha tipificado de forma matizadamente diferente a como lo hace ahora el Código vigente, la participación y el auxilio ejecutivo al suicidio y, por otra, ha introducido, por primera vez, una fórmula legislativa expresa para reprimirpenalmente determinadas especies de eutanasia.

El problema de la punición penal de la participación y el auxilio ejecutivo al suicidio, oel de la punición de determinadas formas de eutanasia, pasa ineludiblemente por una previa reflexión acerca de cuáles sean los límites constitucionales a la disponibilidad de la propia vida. De esta forma, si se considera que la vida es un bien indisponible o irrenunciable y que su protección ha de tener carácter absoluto, al margen de cuál sea el interés o la voluntad del propio titular, entonces habrá que aceptar, sin cuestión, que el consentimiento en este terreno es irrelevante y que se debe castigar cualquier forma de ejecución o de participación en actos tendentes a poner fin a una vida humana, aunque sea con el consentimiento del sujeto pasivo, pudiendo equipararse la penalidad de estos supuestos a la que se impone en los actos de ejecución o de participación en un delito de homicidio no consentido. Sin embargo, si parte de la idea de que la vida es un bien renunciable o disponible por parte de su titular, habrá que reflexionar acerca de cuál deba ser la naturaleza y eficacia del consentimiento en esta cuestión y de cuáles los límites a la punición de los comportamientos de ejecución o de particpación en actos suicidas o eutanásicos, no resultando ya tan fácil justificar la existencia de preceptos como el vigente art. 409 del Código penal, al menos en los términos en los que éste está ahora redactado.

No es ésta la primera vez que tenemos la oportunidad de exponer nuestro pensamiento acerca de todas estas cuestione ${ }^{27}$, pero lo vamos a intentar resumir en unas breves líneas. Comenzaremos por decir, que, en nuestra opinión, de la Constitución española de 1978 no se puede deducir ni el carácter absoluto de la protección a la vida ni el de su indisponibilidad. Es cierto, y nada hay que objetar a

\footnotetext{
${ }^{26}$ Así, con una cierta ironía, COBO DEL ROSAL, M. y BARBONELL MATEU, J. C., en Cobo del Rosal, M. y otros: Derecho Penal. Parte Especial, 3르 ed., Valencia, 1990, p. 543.

${ }^{27}$ Véase, DEL ROSAL BLASCO, B.: «La participación y el auxilio ejecutivo al suicidio: un intento de reinterpretación constitucional del artículo 409 del Código penal», en Anuario de Derecho Penal y Ciencias Penales, II, 1987, 73ss.
} 
ello, que el derecho a la vida del art. $15^{28}$ tiene el sentido de una garantía frente al Estado, que debe proteger y respetar ésta ${ }^{29}$, pero lo que no podemos compartir es que de dicho precepto se pueda deducir, de una parte, que el carácter de dicha protección sea absoluto y, de otra, que el sujeto no tenga la libre disposición sobre su propia $v^{\text {vida }}{ }^{30}$. El derecho a la vida reconocido en el art. 15 de la Constitución se encuentra indisolublemente ligado con el valor jurídico fundamental de la dignidad de la persona, reconocido en el art. $10^{31} \mathrm{del} \mathrm{mismo} \mathrm{texto} \mathrm{constitucional.} \mathrm{Es} \mathrm{más,} \mathrm{como} \mathrm{ha}$ señalado nuestra doctrina constitucional ${ }^{32}$, la dignidad de la persona es «el núcleo desde el que irradian su proyección los valores constitucionalizados», entrañando dicho concepto - -el de dignidad de la persona-, «el reconocimiento de una esfera de la vida de los individuos que debe ser regulada y protegida para que el hombre pueda realizarse»; o si se quiere, expresado en otros términos, «la esencia de los derechos y libertades radica en el libre ejercicio de la personalidad, en el pleno despliegue y perfeccionamiento de la persona humana como racionalidad y como sociabilidad», de forma que «la regulación de tales derechos y libertades ha de hacerse respetando su esenciabilidad en el sentido indicado $»^{33}$. Pues bien, dentro de esa esfera de libertad debe entrar, sin ninguna duda, el derecho a la disposición del propio cuerpo y de la propia vida, porque si la vida se tutela no es a causa de su valor social, sino como presupuesto de la participación del individuo en el sistema social; lo que se están tutelando son «las condiciones mínimas de la propia libertad, las cuales posibilitan al individuo participar o noen el sistema social» ${ }^{34}$. Y es que, además, la irrenunciabilidad del derecho a la vida sólo se puede justificar desde concepciones utilitaristas o colectivistas, o desde posiciones morales muy determinadas que, normalmente, a su vez, se apoyan en principios utilitaristas o colectivistas.

En resumen, pues, de nuestra Constitución lo que realmente parece deducirse es el derecho que toda persona tiene a la libre disposición de la vida ${ }^{35}$. No obstante, dada

${ }^{28} \mathrm{La}$ Constitución Española de 1978 establece, en su art. 15, que «todos tienen derecho a la vida y a la integridad física y moral, sin que, en ningún caso, puedan ser sometidos a tortura ni a penas o tratos inhumanos o degradantes. Queda abolida la pena de muerte, salvo lo que puedan disponer las leyes penales militares para tiempos de guerra».

${ }^{29}$ Así lo ha puesto de manifiesto, RODRIGUEZ MOURULLO, G.: «Derecho a la vida y a la integridad personal y abolición de la pena de muerte», en Comentarios a la Legislación Penal, tomo I: Derecho Penal y Constitución, Madrid, 1982, p. 79.

${ }^{30}$ Con más detenimiento, véase, DEL ROSAL BLASCO, C.: ADPCP, cit. nota 27, p. 85.

${ }^{31}$ Este precepto establece: «La dignidad de la persona, los derechos inviolables que le son inherentes, el libre desarrollo de la personalidad, el respeto a la ley y a los derechos de los demás son fundamento del orden político y de la paz social».

${ }^{32}$ SANCHEZ GONZALEZ, S.: «Derechos y deberes fundamentales», en Comentarios a las Leyes Políticas. Constitución Española de 1978, tomo II, Madrid, 1984, p. 33.

${ }^{33}$ LUCAS VERDU, O.: «Los títulos preliminares y primero de la Constitución y la interpretación de los derechos y libertades fundamentales», en Revista de la Facultad de Derecho de la Universidad Complutense de Madrid, monográfico 2, 1979, p. 25.

${ }^{34}$ BERDUGO GOMEZ DE LA TORRE, I.: El delito de lesiones, Salamanca, 1982, p. 71.

${ }^{35}$ En el mismo sentido, VALLE MUÑIZ, J. M.: «Relevancia jurídico-penal de la eutanasia», en Cuadernos de Política Criminal, núm 37, 1989, pp. 164ss. 
la inmensa importancia del bien jurídico al que ahora nos estamos refiriendo - la vida - así como la gravedad que implica el acto de disposición del mismo, y dada la ineludible obligación que tiene el Estado de proteger la vida, lo que sí debe hacer éste es establecer una regulación de la prestación del consentimiento y unos límites a la eficacia del mismo. De tal forma que el Estado, por una parte, puede exigir que el sujeto para disponer libremente de su vida sea plenamente consciente de la trascendencia y gravedad del acto que realiza y, por otra, puede limitar la eficacia justificante del consentimiento hasta el punto de no ofrecer cobertura a determinadas intervenciones de terceros en el libre acto del suicida.

Lo primero excluiría la posibilidad de considerar como libre el acto suicida de un menor o de un incapaz, pudiendo en estos casos el Estado proteger la vida, incluso, en contra de la voluntad de su titular. Lo segundo nos podría llevar a la conclusión de que, aunque el Estado no puede ni debe imponer el respeto a la propia vida, manteniéndola indemne aún en contra de la voluntad de su titular, sí que podría, sin embargo, obligar a los individuos a respetar la vida ajena, prohibiendo determinados comportamientos que, por parte del tercero no titular de la vida, suponen una efectiva lesión de la vida ajena, aún con el expreso deseo de su titular. Esto convertiría en punibles, directamente, los llamados comportamientos de auxilio ejecutivo al suicidio.

Ahora bien, la imposición del repeto a la vida ajena podría, igualmente, convertir en punibles comportamientos que no son de ejecución directa de la muerte, sino de participación, no ejecutiva, en una conducta suicida ajena. Nos referimos, en concreto a aquellos comportamientos que, de facto, implican una interferencia en la libre formación de la voluntad suicida ajena, bien porque hacen surgir esta voluntad allí donde antes no existía (inducción), bien porque impulsan o determinan definitivamente (cooperación necesaria) una voluntad suicida preexistente. Y esto es así porque son estos los únicos supuestos en los que - a nuestro entender- se puede decir que la libertad interna del acto suicida no es total o absoluta, ya que la decisión suicida viene determinada o motivada «desde fuera», contribuyendo, por tanto, el tercero decisivamente a la lesión del bien jurídico ${ }^{36}$.

Este mismo criterio es que parece haber aceptado el PCP 1992, porque, a diferencia del texto vigente, excluye de forma expresa la punición de los supuestos de mera complicidad, o complicidad no necesaria, en un suicidio ajeno, castigando, eso sí, la inducción (art. 147.1) y la cooperación necesaria (art. 147.2). Por lo demás, el legislador del texto prelegislativo parece ser consciente del menor reproche que ha de merecer quien coopera en actos de participación o de auxilio ejecutivo en un suicidio ajeno que quien lo hace en un homicidio no consentido, porque la penalidad abstracta de aquéllos actos se rebaja respecto de la prevista para el homicidio.

\footnotetext{
${ }^{36}$ Con más detenimiento, en DEL ROSAL BLASCO, B.: ADPCP, cit. nota 27, pp. 87ss.
} 
Lo que, sin embargo, no se justifica suficientemente es el por qué de castigar con una pena más grave la inducción que la cooperación, cuando en la Parte General del PCP 1992 ambas conductas están equiparadas a formas de autoría y se castigan igual, con la pena que les corresponda a los autores.

Ya para concluir nos referiremos a la nueva tipificación que se introduce en el art. 147.4 del PCP 1992, y que pretende abarcar el castigo de determinadas formas de eutanasia consentida, desplazándose, por tanto, en estos supuestos la posible aplicación de la cooperación necesaria o el auxilio ejecutivo al suicidio y rebajándose sustancialmente la pena respecto de estas figuras. Las formas de eutanasia consentida que parecen querer abarcarse expresamente por el novedoso precepto son, sin ninguna duda, las de eutanasia activa directa ${ }^{37}$; es decir, aquellas en las que se realiza un comportamiento expresamente dirigido a causar la muerte de un enfermo terminal o de una persona con graves e insoportables padecimientos permanentes. Más dudoso es si el PCP 1992 pretende, igualmente, recoger los supuestos de eutanasia activa indirecta, es decir, aquellos supuestos en los que la aplicación de determinados medios terapéuticos causarían, con alta probabilidad, la muerte. Con la opinión de otros autores ${ }^{38}$, entendemos que estos son supuestos en los que el comportamiento, por ejemplo, del médico que suministra el calmante, esencialmente para aliviar el dolor, no es típico y deben de quedar excluídos de la punición, pues la conducta no va encaminada a causar activamente la muerte, aunque ésta se asuma como consecuencia, más o menos inevitable, del tratamiento. Más bien parece que en estos casos el médico, cuando esta muerte aparece como inevitable en el horizonte o los dolores resultan absolutamente insoportables, lo que hace es cumplir con su obligación al suministrar los medicamentos que alivian el dolor y su conducta, por ello, ha de entenderse excluida del ámbito de las valoraciones del Derecho Penal. Finalmente, los supuestos que de forma obvia sí han quedado excluídos de la punición por la fórmula utilizada en el PCP 1992 son los de eutanasia pasiva, esto es, aquellos casos en los que no se adoptan medidas tendentes a prolongar la vida o en los que se interrumpe un tratamiento médico que podría calificarse de inútil.

En términos generales, la regulación que de estas formas de eutanasia consentida realiza el PCP 1992 no me parecen, desde un punto de vista político criminal, convincentes. Entiendo que el texto ofrecido por el Gobierno adolece de una gran timoratez y que debería de haberse ido a una despenalización expresa de la eutanasia activa, en cualquiera de sus manifestaciones, estableciéndose las prescripciones que se entiendan deban ser oportunas para garantizar la emisión libre y espontánea el consentimiento. Pero con una solución como la que se adopta lo único que se

\footnotetext{
${ }^{37}$ Sobre las especies de eutanasia relevantes para el Derecho penal, conforme al texto hoy vigente, v. VALLE MUÑIZ, J. M.: CPC, cit. nota 35 , pp. 168 ss.

${ }^{38}$ Así, VALLE MUÑIZ, J. M.: CPC, cit. nota 35, p. 183.
} 
consigue es involucrar al Derecho penal, de forma un tanto estúpida, en la dinámica de una problemática que, en ningún caso, va a ser capaz de solucionar o aminorar, sobre todo si tenemos en cuenta que la eficacia intimidatoria de la sanción penal establecida para la eutanasia consentida es muy baja. Y lo cierto es que no se comprende muy bien qué es lo que se pretende con tal norma, pues la eutanasia, como fenómeno criminal, tiene hoy por hoy una incidencia prácticamente nula. Más parece que lo que se ha pretendido es establecer una posición de principio, con fines más o menos inconfesables, pero que difícil es predecir si puede, o en qué medida puede, contribuir al debate sobre la eutanasia que, de momento, no ha hecho más que comenzar.

\section{Proyecto de Código Penal de 1992}

Art. 142. El que matare a otro será castigado, como reo de homicidio, con la pena de prisión de diez a quince años.

Art. 143. Será castigado, como reo de asesinato, con la pena de prisión de quince a veinte años, el que matare a otro concurriendo alguna de las circunstancias siguientes:

$1^{\text {a }}$. Alevosía.

$2^{a}$. Por precio, recompensa o promesa.

33. Con ensañamiento, aumentando deliberada e inhumanamente el dolor del ofendido.

Art. 144. Cuando en un asesinato concurrieren dos o más agravantes genéricas se impondrá la pena de veinte a veinticinco años.

Art. 145. La conspiración, proposición y provocación para cometer los delitos de homicidio o asesinato serán castigados con la pena inferior en uno o dos grados a la del delito correspondiente.

Art. 146. 1. El que por imprudencia grave causare la muerte de otro será castigado, como reo de homicidio imprudente, con la pena de prisión de uno a tres años.

2. Cuando el homicidio imprudente fuere cometido utilizando un vehículo de motor se impondrá asimismo la pena de privación del derecho a conducir por término superior a uno y hasta seis años.

Art. 147. 1. El que induzca al suicidio de otro será castigado con la pena de prisión de cuatro a ocho años. 
2. Se impondrá la pena de prisión de dos a cinco años al que cooperare con actos necesarios al suicidio de una persona.

3. Será castigado con la pena de prisión de seis a diez años si la cooperación llegare hasta el punto de ejecutar la muerte.

4. El que causare o cooperare activamente con actos necesarios a la muerte de otro, por la petición expresa y seria de éste, en el caso de que la víctima sufriera una enfermedad grave que hubiera conducido necesariamente a su muerte, o que produjera graves padecimientos permanentes y difíciles de soportar, será castigado con la pena inferior en uno o dos grados a las señaladas en los números 2 y 3 de este artículo. 